\title{
ARTIGOS
}

\section{A INDUSTRIA CERÂMICA DA LOUÇA \\ UTILITÁRIA E DECORATIVA NA PERSPECTIVA \\ DAS ESTRATÉGIAS DO LANÇAMENTO DE \\ NOVOS PRODUTOS DE ECO-DESIGN}

\author{
JOSÉ MANUEL COUCEIRO BAROSA CORREIA FRADE, Dr. | IPLERIA \\ PAULO CESAR MACHADO FERROLI, Dr. |UFSC
}

\begin{abstract}
RESUMO
Este artigo pretende evidenciar estratégias de eco-design e de sustentabilidade que são aplicadas no processo de design de novos produtos em empresas dos subsetores industriais da cerâmica utilitária e decorativa em portugal. A divulgação deste trabalho pretende servir como fonte de inspiração ao design de futuros produtos que se diferenciem por serem ambientalmente adequados, economicamente viáveis e socialmente responsáveis, fatores que são cada vez mais importantes nos critérios de decisão dos consumidores nomeadamente dos mercados internacionais mais exigentes e evoluídos onde as empresas portuguesas comercializam os seus produtos.
\end{abstract}

PALAVRAS CHAVE: Eco-design; Sustentabilidade; Cerâmica, Louça; Decorativo

\section{ABSTRACT:}

This article aims to highlight the ecodesign and sustainability that are applied in the design process of new products in companies in the industrial subsectors of utilitarian and decorative ceramics in Portugal. The disclosure of work intends to serve as a source of inspiration for the design of future products that differ because they are suitable environmental, economically viable and socially responsible, factors that are increasingly important in the decision criteria of consumers, particularly in the most demanding and evolved international markets. where Portuguese companies market their products.

KEYWORDS: Eco-design; Sustainability; Ceramics, Dishware; Decorative 


\section{INTRODUÇÃO}

Uma das estratégias que visa otimizar os produtos do ponto de vista do seu impacto ecológico é conseguir "fazer mais com menos" (matéria, energia, emissões poluentes), com vantagens sobre a competitividade da própria indústria pela redução dos custos gerais de produção que esta estratégia potencia. Por outro lado, as empresas portuguesas procuram que os seus produtos atinjam os mercados globais, sendo estratégicos certos mercados que cada vez mais aplicam critérios ambientais na decisão de compra de produtos. Por esta razão têm surgido recentemente em Portugal vários estudos e investigações que procuram identificar as estratégias de eco-design e de sustentabilidade que têm sido aplicadas no projeto de novos produtos nomeadamente cerâmicos. Em consequência, o ecodesign e a sustentabilidade têm merecido especial atenção pelas indústrias cerâmicas [1,3] e têm sido critérios a que o projeto de design tem frequentemente atendido como forma de diferenciação dos produtos [4].

Do ponto de vista da engenharia da conformação de produtos cerâmicos, produzir espessuras de parede dos objetos cerâmicos abaixo de uma espessura crítica tem implicações ao nível da complexidade produtiva e da resistência mecânica dos objetos, que limitam a aplicação prática desta estratégia. São evidentes projetos de produtos que têm em consideração preocupações ambientais que seguem outras estratégias tais como selecionar materiais e tecnologias de produção de baixo impacto ambiental, otimizar as várias etapas na análise do ciclo de vida do produto, implementar objetivos de economia circular, entre outros.

É importante estudar novos produtos industriais cerâmicos de louça e decorativos no sentido de procurar identificar outras estratégias que conduzam, na prática industrial dos vários subsetores cerâmicos, a produtos ecologicamente mais adequados, ou mesmo mais sustentáveis, inclusivamente para inspirar a criação de novos produtos. Este artigo pretende ampliar a investigação das estratégias de ecodesign ou da sustentabilidade a partir do estudo de produtos recentes integrados em portefólios de industrias cerâmicas portuguesas do subsetor da louça utilitária e dos produtos decorativos.

\section{RESULTADOS E DISCUSSÃO}

Ao nível de produção, o sector utilitário e decorativo integra uma grande variedade de produtos tais como pratos e travessas de diferentes formatos, taças e canecas de diferentes volumetrias, bules e chávenas de diferentes formas e toda uma panóplia de artigos decorativos cujo limite é a inspiração dos seus criadores conjugada com a capacidade dimensional e formal de execução das peças definida pelos próprios limites das tecnologias de conformação disponíveis para a materialização destes produtos.

Do ponto de vista material este subsetor utiliza todos os tipos de pastas cerâmicas: barro vermelho, faianças, grés e porcelanas. Nestes quatro tipos de pastas podem-se utilizar métodos de conformação mecânica simples como prensagem plástica, produção por roller e enchimento de moldes de gesso.

Nas pastas de grés e de porcelana usam-se, ainda, o enchimento com pressão (que aumenta a produtividade relativamente ao enchimento com barbotina de moldes de gesso) e a prensagem isostática que permite uma densificação em verde mais alta e por isso é compatível com ciclos térmicos de cozedura mais rápidos nomeadamente monocozedura.

As temperaturas de cozedura e a resistência mecânica dos produtos finais sem defeitos são crescentes no seguinte sentido: barro vermelho, faiança, grés e porcelana respetivamente com cores após cozedura vermelha, beje, beje acinzentada e branca (por definição universal tão translúcida quanto menor for a espessura da parede dos produtos).

Do ponto de vista do acabamento superficial dos produtos, os barros vermelhos utilitários, tal como os produtos decorativos podem ser ou não vidrados, ou ainda, parcialmente vidrados; as faianças utilitárias por serem porosas são sempre vidradas. O nível de porosidade típico do grés é muito baixo, por definição a absorção de água é inferior a 3\% [5], e o nível de porosidade da porcelana é praticamente nulo, por definição a absorção de água é inferior a 0,5\% [5], ainda, assim, é muito comum a vidragem nos produtos produzidos com estas duas pastas cerâmicas tendo em vista introduzir nos produtos finais um acabamento superficial mais liso, mais fácil de higienizar e que garanta total impermeabilidade.

Do ponto de vista das decorações, estes produtos em função das suas formas podem receber tintas aplicadas por pintura manual, pistolagem, serigrafia, tampografia, decalque, impressão gráfica, etc. A impressão gráfica é uma tecnologia mais recente e por isso ainda pouco comum devido ao seu custo de investimento e à impossibilidade de se aplicar a uma grande variedade de formas.

Quase sempre nos produtos utilitários e decorativos produzidos com barros vermelhos é realçada esta cor natural da matéria nos produtos finais.

As faianças, por exigirem menores temperaturas de cozedura do que os grés e as porcelanas, permitem uma maior diversidade na palete de cores dos vidrados e tintas e algumas destas, sobretudo na gama dos vermelhos, laranjas e 
amarelos resultam comparativamente muito mais brilhantes nas primeiras pastas. Por consequência, nos grés as cores apresentam-se mais esbatidas do que nas faianças.

Finalmente é comum diversificar as porcelanas utilitárias para dois mercados principais: restauração e doméstica. Os produtos cerâmicos de porcelana para restauração são quase sempre brancos (porque são vidrados a transparente por forma a evidenciar a cor branca da pasta) com eventuais pequenos apontamentos de cor fundamentalmente no bordo das peças (filetagem). Os serviços domésticos de grande valor económico são muitas vezes decorados com tintas de platina ou ouro (os mais nobres) e azuis cobalto, verde crómio, entre outros, aplicadas manualmente ou indiretamente através das tecnologias já referidas anteriormente.

Independentemente do subsetor cerâmico existem evidentemente aspetos tecnológicos que contribuem decisivamente para o impacto ambiental de cada empresa como é o caso dos tipos de fornos usados e respetiva eficiência energética, combustível utilizado, características dos ciclos térmicos implementados nos respetivos processos, origem das matérias-primas, soluções técnicas de redução do impacto ambiental, etc.

Para além destes fatores é possível encontrar um conjunto de práticas que podem favorecer a adequabilidade ambiental dos produtos cerâmicos projetados pelas equipas de engenharia e de design das mesmas empresas.

No entanto, é impossível falar de design industrial cerâmico sem abordar este assunto dentro das especificidades de cada subsetor industrial, embora algumas das estratégias percecionadas sejam comuns a vários subsetores.

O design industrial deve integrar o bom desenho nomeadamente o boleamento das arestas dos produtos, a inexistência de variações bruscas de material e outros fatores concentradores locais de tensões que facilitam as quebras durante a fabricação e no uso.

Através do estudo de um conjunto de produtos selecionados no presente trabalho, as estratégias de sustentabilidade percepcionadas no subsetor cerâmico utilitário e decorativo são os seguintes:

- - aplicação de estratégias de design emocional que potenciam aumentar o tempo de vida dos produtos, figura 1;

- - utilização de matérias primas de baixo custo e alta disponibilidade local (no caso do barro vermelho), figuras 3 e 4;

- - eliminação total ou parcial de vidragem, sempre que tal não seja fundamental, figura 3;

- - aplicação de soluções de decoração simples e ecológicas como por exemplo altos e baixos relevos (sobretudo na faiança), suspensões argilosas para alteração superficial da cor base do produto, mistura de argilas para modificação da cor base (mais evidente nos barros vermelhos), figura 12;

- - valorização de resíduos industriais de outras empresas, ou da própria empresa, pela sua inclusão no processo cerâmico como matéria prima ou técnica de diferenciação cromática dos produtos, figuras 5 e 6;

- - diferenciação e valorização a partir de materiais de baixo impacto ambiental por vezes endógenos nomeadamente a partir da substituição material de certas peças dos produtos cerâmicos, figuras 7 e 9;

- - produtos com baixa espessura de parede (desmaterialização), figuras 8,11 e 12

- - multifuncionalidade, figuras 4 e 9;

- - design de produtos compatível com a redução da ocupação do espaço no transporte (ou na fase de uso), com consequente minimização de embalagens e dos consumíveis gráficos inerentes (minimização da embalagem), figuras 1, 2, 3 e 7;

- - design e desenvolvimento de produtos direcionados para mercados de maior valor acrescentado como sejam por exemplo o mobiliário, arquitetura, moda ou a iluminação, figura 9;

- - desenvolvimento de outros produtos com base em resíduos próprios vidrados, figura 10;

- - forte inovação nos processos e produtos:

- - produtos baseados na alta produtividade a partir da prensagem isostática compatíveis com produtos economicamente mais acessíveis, dentro do mesmo tipo de pasta, figuras 11, 12, 13 e 14;

- - produtos compatíveis com monocozedura rápida - com menores consumos de energia e menor emissões de gases poluentes, figuras 11, 12, 13 e 14;

- $\quad$ - produtos vidrados a transparente (sem a presença de óxidos de metais de transição na composição dos vidrados, a maioria dos quais com forte impacto ambiental), figuras 12 e 14;

- - produtos de pasta pigmentada com óxidos de metais de transição encapsulados por um vidrado transparente de baixo impacto ambiental, figura 13;

- $\quad$ - pastas de alta resistência mecânica compatíveis com tempos de vida dos produtos mais prolongados; figura 14. 

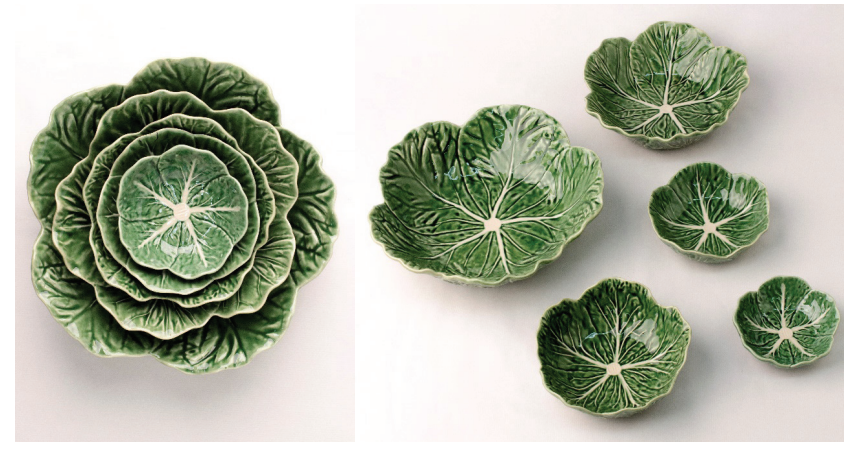

Figura 1 - Coleção de 5 contentores com a forma de couve em faiança vidrada com o vidrado designado "verde caldas"; peças dereferencia na identidade cultural da louça utilitária e decorativa das caldas da Rainha, originalmente criada pelo ceramista Bordallo Pinheiro (empresa Bordallo Pinheiro).

Fonte: Autores.
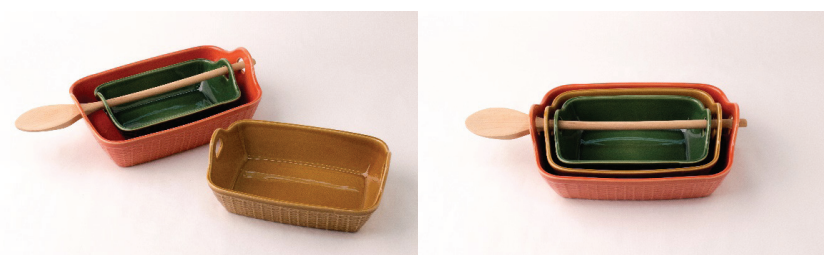

Figura 2 - Coleção de tabuleiros utilitários em faiança vidrada, com encaixe entre si (empresa Matcerâmica).

Fonte: Autores.
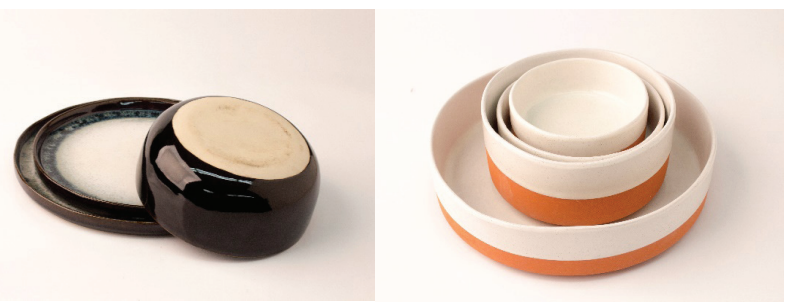

Figura 3 - Peças parcialmente vidradas, à esquerda grés (empresa Grestell), à direita barro vermelho (empresa Valdosol).

Fonte: Autores.
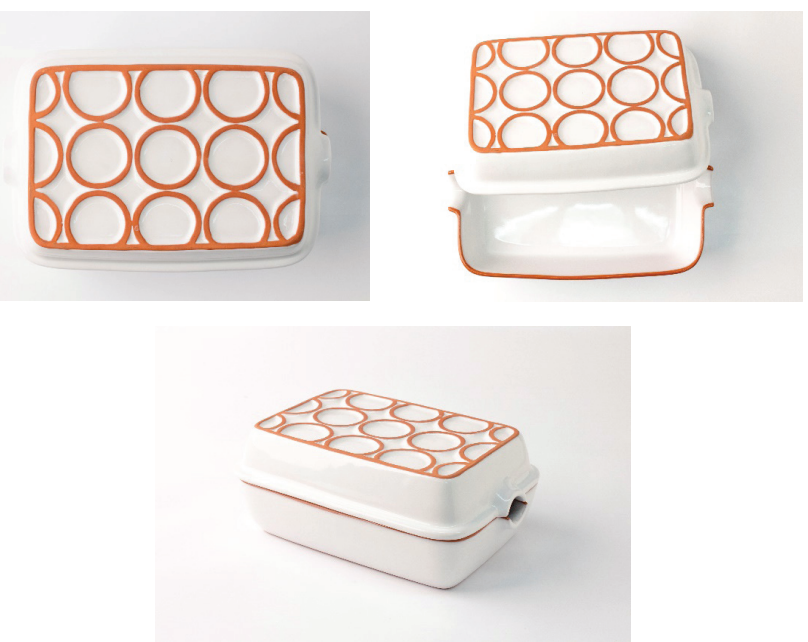

Figura 4-Pormenores de alto relevo decorativo em contentores de barro vermelho cujo contraste cromático / decorativo resulta da existência de zonas vidradas e não vidradas (empresa Valdosol). Fonte: Autores.
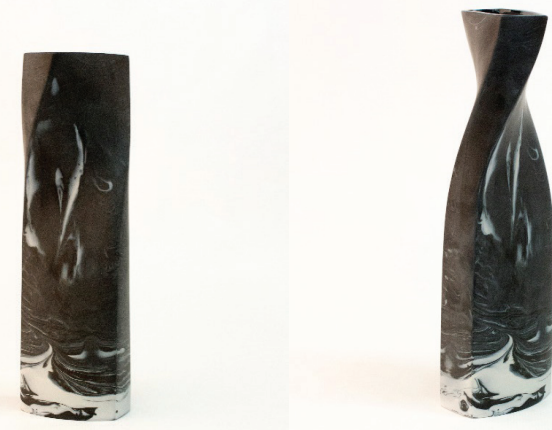

Figura 5 - Pormenor do contraste cromático resultante de uma pasta negra de porcelana obtida pela incorporação de resíduos na sua composição, (empresa Vista Alegre). Fonte: Autores.

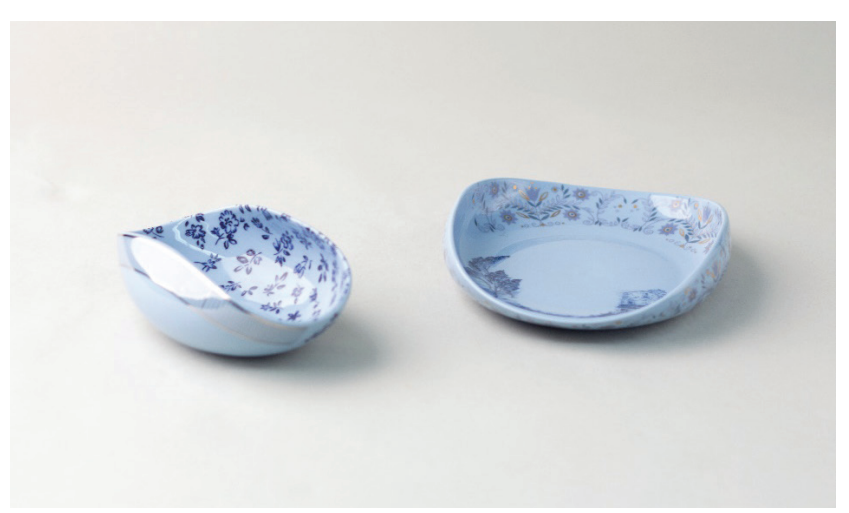

Figura 6 - Conjunto de taças em porcelana cuja pasta integrou resíduos recolhidos na estação de tratamento de águas da própria empresa e os decalques (residuais) decorativos eram para aplicação noutros produtos descontinuados (designer Alda Tomás, empresa SPAL). Fonte: Autores.

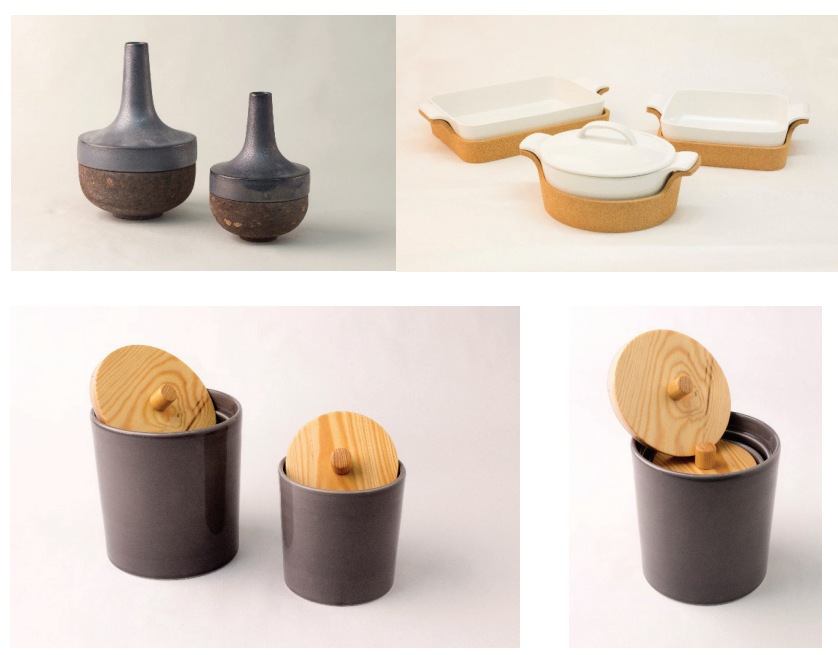

Figura 7 - Em cima: conjunto de peças com complementos de cortiça, à esquerda contentores decorativos em faiança e base em cortiça residual (empresa Jomaze); à direita louça de ir ao forno em grés (empresa Grestel); em baixo: conjunto de peças com complementos em madeira Matcerâmica). Fonte: Autores. 


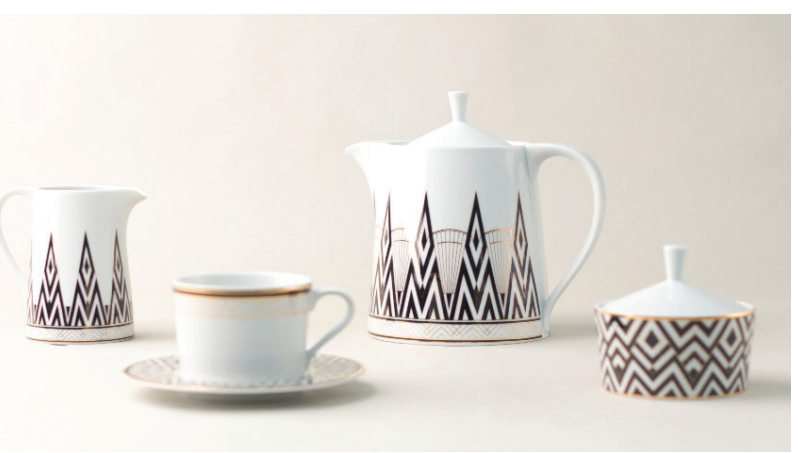

Figura 8 - Peças de serviço de café em porcelana vidrada e decorada com decalque e filete a ouro, com muito baixa espessura de parede (empresa SPAL).

Fonte: Autores.

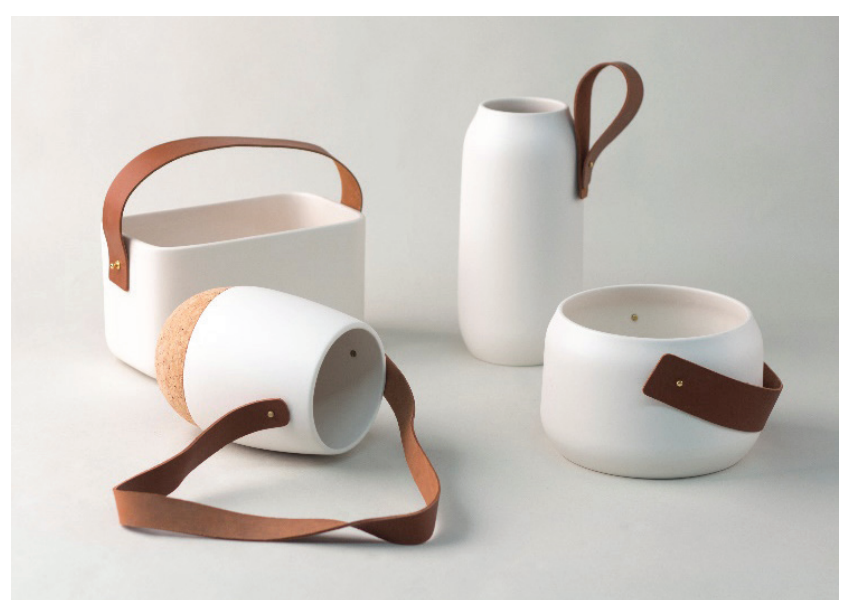

Figura 9 - Produtos em faiança com complementos em couro e sistemas inovadores de fixação metálicos propondo novos campos de aplicação (empresa Jomaze).

Fonte: Autores.

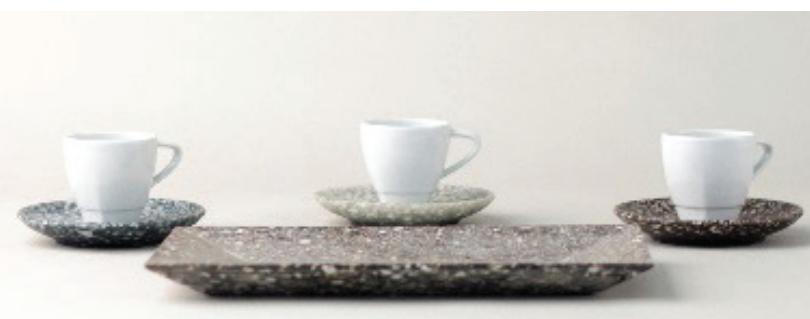

Figura 10 - Coleção de produtos obtidos por prensagem de resinas carregadas com caco vidrado (de peças cerâmicas rejeitadas no controlo de qualidade) moído (empresa SPAL). Fonte: Autores.
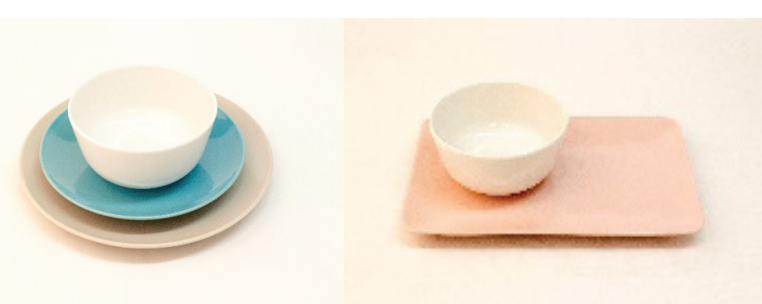

Figura 11 - Coleção de produtos de grés de baixa complexidade formal conformados por prensagem isostática e processados por monocozedura (empresa Riastone).

Fonte: Autores.

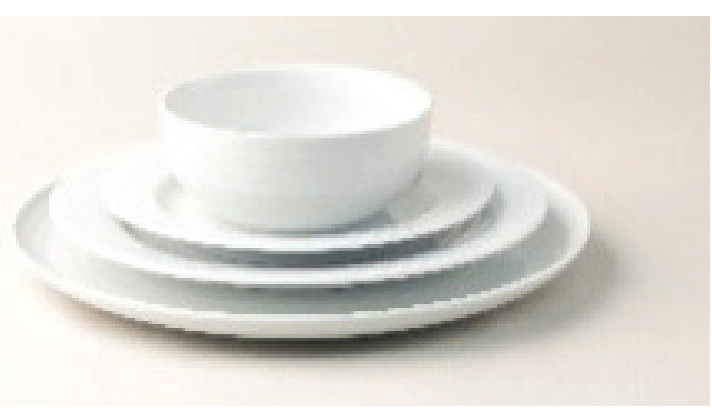

Figura 12 - Coleção Roulette dos designers David Queensberry e Martin Hunt de produtos de porcelana vidradas a transparente com linha muito simples conformados por prensagem isostática e processados por monocozedura que se mantêm há cerca de duas décadas como uma das coleções mais vendidas pela empresa conforme informação prestada pela mesma (empresa SPAL). Fonte: Autores.

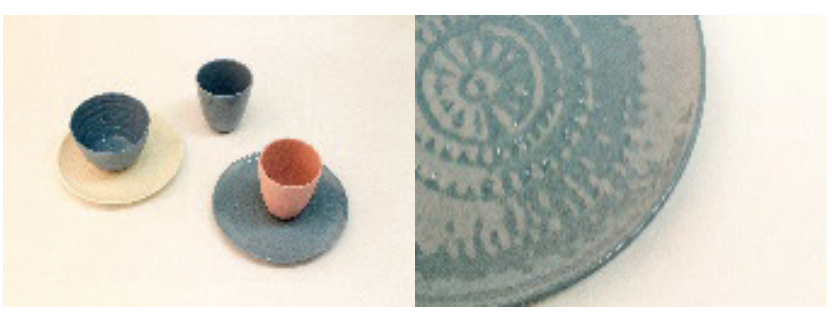

Figura 13 - Coleção de produtos em grés conformados com pastas pigmentadas vidradas a transparente (empresa Cerexport). Este grés com alto relevo na superfície pode ter contato com chama direta, ir ao forno e ser usado na mesa conferindo-Ihe um caráter multifuncional. Fonte: Autores.

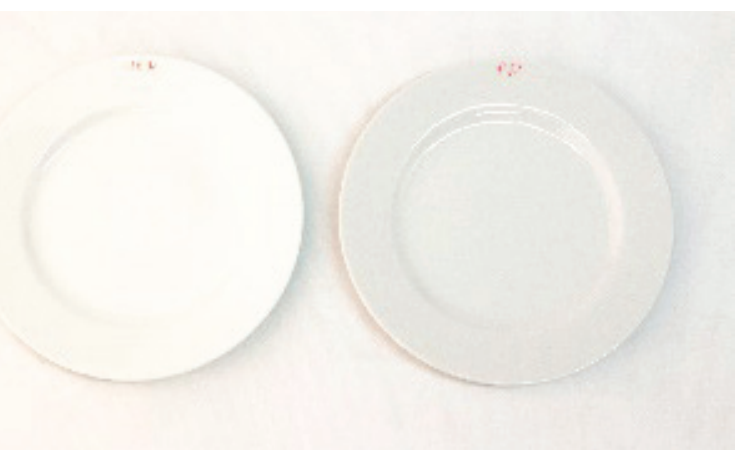

Figura 14 - Pratos de porcelana de hotel, à esquerda porcelana de alta resistência, à direita porcelana de resistência normal (empresa Vista Alegre).

Fonte: Autores.

\section{CONCLUSÕES}

Este trabalho a partir do estudo de outros produtos industriais permite reforçar um conjunto de conclusões já observadas em trabalhos anteriores dos mesmos autores.

Os novos produtos objeto de investigação no presente trabalho permitem reforçar a conclusão de que o mercado do subsector utilitário e decorativo parece continuar a privilegiar o desenho e produção de produtos com base nas tendências estéticas - as ditas "modas", cujos ciclos de vida são normalmente curtos. Talvez por esta razão a procura de projetos sustentáveis dentro deste subsector é mais difícil por ser menos evidente. No entanto, é certo que as estratégias de ecodesign podem potenciar 
o aumento da qualidade dos produtos tanto através da melhoria das suas características físicas, como da qualidade da superfície das peças cerâmicas (durabilidade com testes de resistência mecânica e química, testes de resistência do vidrado, etc.) inclusivamente através de bons desenhos que tornem por exemplo tais produtos mais seguros para os seus utilizadores.

Os novos produtos objeto de investigação no presente trabalho permitem reforçar a conclusão de que de que a análise crítica dos produtos deste subsetor permite evidenciar certos objetos com carácter ecoinovador, destacando-se a inclusão de outros materiais (madeira, cortiça, metal - quer pelo uso de materiais comparativamente mais sustentáveis, quer pela iniciativa social que permite a alguns artesões), desenhos de produtos que permitem o empilhamento e encaixe (que facilita o transporte, a distribuição e a arrumação, reduzindo o espaço necessário para o transporte e uso), o caráter multifuncional do uso, a utilização de vidrados transparentes de baixo impacto ambiental (comunicando a cor da pasta natural ou pigmentada), a utilização de lamas de estações de tratamentos de águas residuais como componente das pastas, a reutilização de cacos de peças rejeitadas no processo de controlo de qualidade como matéria primas de novos produtos (compósitos de matriz polimérica), a vidragem dos produtos utilitários só no interior - onde é estritamente necessário), a ausência de vidrados em produtos decorativos e desenhos com espessuras mínimas de parede, a procura de ciclos mais rápidos e de monocozedura na fabricação entre outros.

Alicerçados pela atualidade do tema da economia circular, o reforço da tentativa de incorporação de resíduos industriais provenientes de outros subsetores industriais nomeadamente nas pastas cerâmicas, ou mesmo como combustível, pode ser também uma oportunidade para este subsetor cerâmico.

Este estudo permitiu identificar um conjunto de práticas de design que parecem conduzir ao projeto de produtos ambientalmente mais adequados.

A divulgação de tais práticas ou estratégias podem vir a motivar, quer em ambiente académico, quer em meio industrial, a criação de outros produtos cerâmicos que se pretendem sustentáveis e inovadores.

\section{AGRADECIMENTOS}

Adriana César, Lia Gomes; Liliana Gouveia e Pedro Cá pelos créditos fotográficos.

O Projeto CP2S, "Cerâmica, Património e Produto

Sustentável - do ensino à indústria", agradece o apoio FEDER - Fundo Europeu de Desenvolvimento Regional, no âmbito do Programa Portugal 2020 - Programa Operacional Regional do Centro (CENTRO-01-0145-FEDER-23517).

\section{REFERÊNCIA}

CERÂMICA DE MESA PORTUGUESA: o contributo deste sector para a sustentabilidade; APICER - Associação Portuguesa das Indústrias de Cerâmica e de Cristalaria; (2015).

Pereira, P. M. R.; Análise e melhoria do processo de fabrico de louça de hotelaria; Universidade do Porto; (2018).

Bissolvil-Dalvi, M.; Costa, L.M e outros; Avaliação comparativa do índice de sustentabilidade da cerâmica e das rochas ornamentais através da ferramenta ISMAS; Euro Elecs 2017; (2017).

Rocha, C.; O papel do Ecodesign na Eficiência Energética dos Produtos Cerâmicos; http://repositorio.Ineg.pt/handle/10400.9/2403 (acesso em janeiro 2021).

Norma Portuguesa Louça Cerâmica Utilitária Parte 1 Especificações - -NP4555-1; (2018). 


\section{AUTORES}

JOSÉ MANUEL COUCEIRO BAROSA CORREA FRADE, Dr. | Instituto Politécnico de Leiria | IPL - LIDA - ESAD-CR| Caldas da Rainha - Portugal | Correspondência para: Rua Isidoro Inácio Alves de Carvalho, Campus 3, 2500-321 Caldas da Rainha - Portugal | E-mail: jose.frade@ipleiria.pt

ORCID: https://orcid.org/0000-0002-6675-672X

PAULO CESAR MACHADO FERROLI, Dr. | Universidade Federal de Santa Catarina - UFSC | Virtuhab| Florianópolis, SC. Brasil | Correspondência para: Campus Universitário Reitor João David Ferreira Lima, s/nº Trindade - Florianópolis - SC CEP: 88040-900 | E-mail: pcferroli@gmail.com

\section{COMO CITAR ESTE ARTIGO}

FRADE, José Manuel Couceiro Barosa Correia; FERROLI, Paulo Cesar Machado. A Industria Cerâmica Da Louça Utilitária E Decorativa Na Perdspetiva Das Estratégias Do Lançamento De Novos Produtos De Eco-Design. MIX Sustentável, [S.I.], v. 7, n. 4, p. 83-90, set. 2021. ISSN 24473073. Disponível em:<http://www.nexos. ufsc.br/index.php/mixsustentavel>. Acesso em: dia mês. ano. doi:https://doi.org/10.29183/2447-3073. MIX2021.v7.n4.83-90. 
